\title{
Male more than female infants imitate propulsive motion
}

\section{Citation}

Benenson, Joyce. F., Robert Tennyson, and Richard W. Wrangham. 2011. "Male More Than Female Infants Imitate Propulsive Motion." Cognition 121, no. 2: 262-67.

\section{Published Version}

doi:10.1016/j.cognition.2011.07.006

\section{Permanent link}

http://nrs.harvard.edu/urn-3:HUL.InstRepos:12712845

\section{Terms of Use}

This article was downloaded from Harvard University's DASH repository, and is made available under the terms and conditions applicable to Open Access Policy Articles, as set forth at http:// nrs.harvard.edu/urn-3:HUL.InstRepos:dash.current.terms-of-use\#OAP

\section{Share Your Story}

The Harvard community has made this article openly available.

Please share how this access benefits you. Submit a story.

\section{Accessibility}


in press Cognition

Male more than Female Infants Imitate Propulsive Motion

Joyce. F. Benenson $^{1,2} \quad$ Robert Tennyson $^{1} \quad$ Richard W. Wrangham ${ }^{1}$

1. Department of Human Evolutionary Biology, Harvard University, 11 Divinity Avenue, Cambridge, MA 02138, USA

2. Department of Psychology, Emmanuel College, 400 The Fenway, Boston, MA 02115, USA

Address correspondence to:

Joyce Benenson

Department of Psychology

Emmanuel College

400 The Fenway

Boston, MA 02115, USA

and

Department of Human Evolutionary Biology

Harvard University

11 Divinity Avenue

Cambridge, MA 02138 USA

Correspondence to: Email: joyce.benenson@gmail.com

Word Count: 2996

Keywords: infancy, imitation, sex differences, propulsive movement 


\begin{abstract}
Few experimental studies investigate the mechanisms by which young children develop sextyped activity preferences. Gender self-labeling followed by selective imitation of same-sex models currently is considered a primary socialization mechanism. Research with prenatally androgenized girls and non-human primates also suggests an innate male preference for activities that involve propulsive movement. Here we show that before children can label themselves by gender, 6- to 9-month-old male infants are more likely than female infants to imitate propulsive movements. Further, male infants' increase in propulsive movement was linearly related to proportion of time viewing a male model's propulsive movements. We propose that male sextyped behavior develops from socialization mechanisms that build on a male predisposition to imitate propulsive motion.
\end{abstract}




\subsection{Introduction}

How humans develop sex-typed activity preferences and interests generates much controversy. Cross-culturally, sex differences in activities and interests emerge around 18 months (Gosso, Otta, Morais, Ribeiro, \& Bussab, 2005; Huston, 1986; Ruble, Martin, \& Berenbaum, 2006) and continue throughout life (Wood \& Eagly, 2002). Beginning in the second year, boys exhibit greater interest than girls in transportation vehicles, weapons, tools, and rough-and-tumble play, whereas girls prefer dolls and objects associated with domestic activities (Huston, 1986; Ruble, et al., 2006).

Two predominant socialization explanations exist for early sex-typed activity preferences. According to the first, children learn to categorize themselves as male or female, then preferentially imitate same-sex adult and peer models. Between 17-21 months, when gender self-labeling begins to emerge, use of gender labels is associated for boys with play with a truck over a doll and for girls with the reverse (Zosuls et al., 2009). Even before boys could label themselves by gender however, they preferred trucks more than girls did (Zosuls et al., 2009). This suggests that another earlier mechanism likely exists.

A second socialization explanation rests on reinforcement. In a meta-analysis of sextyped parental treatment of children, parents encouraged sex-typed activities and household chores (Lytton \& Romney, 1991). Thus, parents may reward boys more than girls for playing with trucks. Reinforcement however may build upon innate predispositions (Öhman \& Mineka, 2003; Scarr \& McCartney, 1983).

Two sources support the role of innate predispositions. First, beginning in early 
childhood, prenatally androgenized girls with congenital adrenal hyperplasia $(\mathrm{CAH})$ more than controls play with vehicles, weapons, and tools (Berenbaum \& Hines, 1992; Berenbaum \& Snyder, 1995; Pasterski et al., 2005).

Second, non-human primates exhibit sex differences in toy preferences that resemble those of humans. Free-roaming male more than female chimpanzees, Pan troglodytes, use sticks for hitting, whereas females as juveniles are more likely to carry sticks as if they were babies (Kahlenberg \& Wrangham, 2010). Further, male vervet monkeys, Cercopithecus aethiops sabaeus, play longer than females with a toy car and ball, whereas females play longer with a doll and pot (Alexander \& Hines, 2002). Likewise, male more than female rhesus monkeys, Macaca mulatta, play longer with wheeled vehicles (Hassett, Siebert, \& Wallen, 2008).

Innate predispositions for perceptual attributes or motor affordances of objects therefore likely provide a foundation for sex-typed activity preferences. Investigating perceptual attributes, researchers presented neonates with a live adult female face and a mobile, one at a time for 70 seconds. Female neonates looked more at the face than the mobile, whereas male infants exhibited the reverse pattern (Connellan, Baron-Cohen, Wheelwright, Batki, \& Ahluwalia, 2000). Likewise, infants 5 months of age viewed a toy truck and a doll side-by-side in two 10second blocks. No sex difference in looking time emerged, but girls fixated more times on the doll than the truck, while boys did not discriminate (Alexander, Wilcox, \& Woods, 2009). Other studies however find early sex-differentiated perceptual preferences only for boys at 9 months (Campbell, Shirley, Haywood, \& Crook, 2000) or not at all (e.g.,Serbin, Poulin-Dubois, Colburne, Sen, \& Eichstedt, 2001).

Motor affordances provide a theoretically appealing foundation for sex-typed activity 
preferences. Males throw more forcefully than females beginning early in childhood (Thomas \& French, 1985). Further, most mammalian male (but not female) sexual and aggressive behaviors require executing a forward thrusting motion. Similarly, young boys' sex-typed activities involving weapons, vehicles, and tools often require a propulsive motion. In support of the hypothesis that propulsion underlies male sex-typed preferences, 3-4-year-old boys who punched a puppet more forcefully were rated by teachers as engaging in more male sex-typed activities and chose more toys that required propulsive movement (Benenson, Liroff, Pascal, \& Della Cioppa, 1997).

Further, Bandura's experiments on imitation suggest that children are primed to learn some movements more rapidly than others, and that one component of physical aggression, propulsive movements, may appeal more to males. Specifically, $90 \%$ of $4-5$-year-old children imitated knocking down a doll, but only $45 \%$ imitated marching across a room (Bandura \& Huston, 1961). Moreover, when 3-5-year-old children viewed a male and female model physically and verbally aggressing against a punching bag doll, boys imitated the physically aggressive movements more than girls, particularly of the male model (Bandura, Ross, \& Ross, 1961). Further, even without a model, boys exhibited more propulsive movements than girls, such as hitting, punching, and gun play. The predominant interpretation has been that boys imitated the male model's aggression because they understood conceptually that they are male and males behave aggressively (Bandura \& Bussey, 1999; Kohlberg, 1966; Martin, Ruble, \& Szkrybalo, 2002; Zosuls et al., 2009). An alternative, but not mutually exclusive interpretation however, is that boys find males' propulsive movements more appealing than females' movements.

Here we test whether boys more than girls will imitate a simple non-aggressive 
propulsive movement of a male model, before gender self-labeling and understanding of maleness and aggression occur. Consequently, we chose 6-9-month-old infants as participants. To control for perceptual preferences, only one object, a balloon, was employed.

\subsection{Materials and Method}

\subsection{Procedure}

Twenty-five male $(M=6.80$ months, $S D=1.22)$ and 20 female $(M=7.21$ months, $S D=$ 1.36) infants participated while waiting for their well-baby visits at a health clinic. One-third of the 45 infants were Caucasian, 1/3 Hispanic, and the remainder came from Black, Asian, and mixed-race backgrounds with similar distributions within sex.

Participating infants were brought to a conference room which contained a large, opaque tent containing the experimental apparatus (see Figure 1). The parent sat on a chair with the

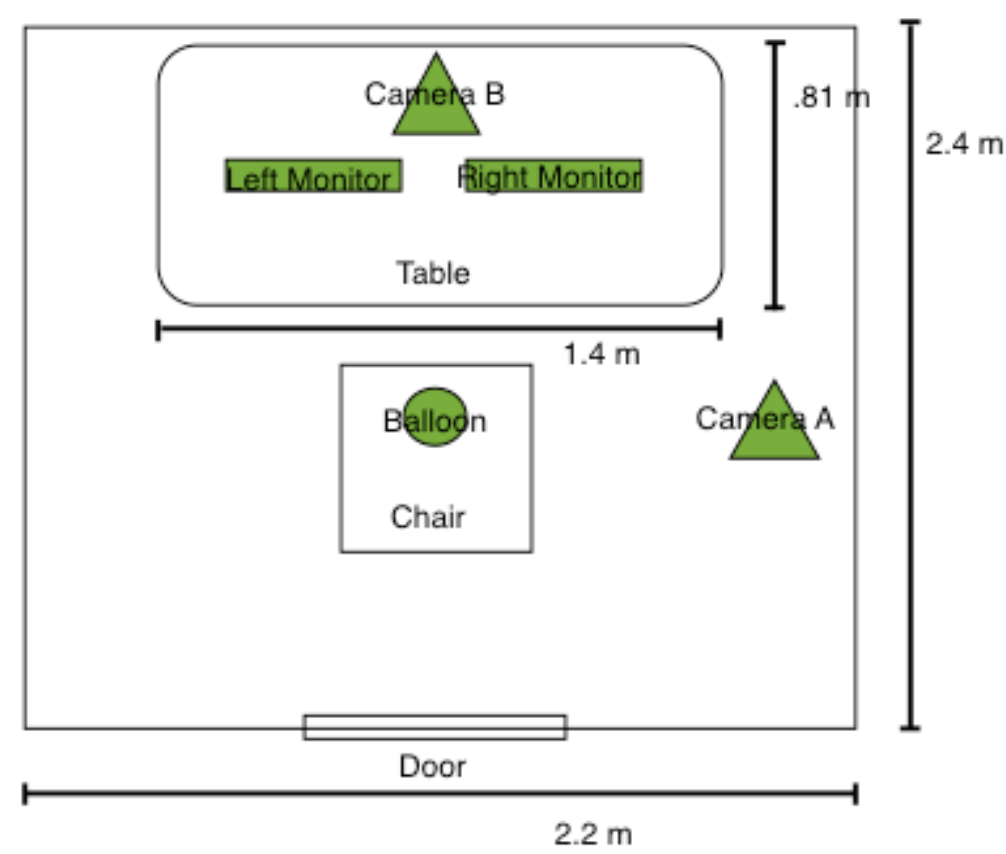

Figure 1 Schematic figure of experimental set-up inside tent. 
infant on his or her lap. They faced two adjacent computer monitors separated by a camera which was positioned to record the infant's looking preferences. A second camera to the right of the infant recorded the infant's arm movements. Once the parent was seated, the parent was asked not to interfere with the infant's movements and not to look at the computer monitors.

The procedure consisted of three parts. In the first part, a 4" diameter mylar balloon (green, red, or blue) was suspended by a thread from the ceiling of the tent in front of the infant for 120 seconds. The infant was free to play with the balloon. To control for perceptual preferences, balloon color was counterbalanced across sex.

In the second part, the balloon was removed, the lights extinguished, and the monitors activated. Each infant watched $326000 \mathrm{~ms}$ pairs of video clips, with each pair of clips separated by $1000 \mathrm{~ms}$, for a total viewing time of 223 seconds. Pairs of clips were projected using splitscreen technology, allowing simultaneous display of the same adult cradling the balloon on one monitor and hitting the balloon on the adjacent monitor, with the two movements alternating sides across clips. Half of the pairs of clips contained a male adult and the other half a female adult, both wearing identical clothing. Each adult faced right in half of the clips and left in the other half, and cradled or hit a red balloon in half of the clips and a blue balloon in the other half. For the cradling movement, the adult held the balloon with two hands on the opposing left and right side of the balloon and gently moved it up and down. For the hitting movement, the adult hit the balloon with one hand. The balloon was attached loosely to a wall, so that hitting it did not cause it to move far (see Figure 2 for examples). 

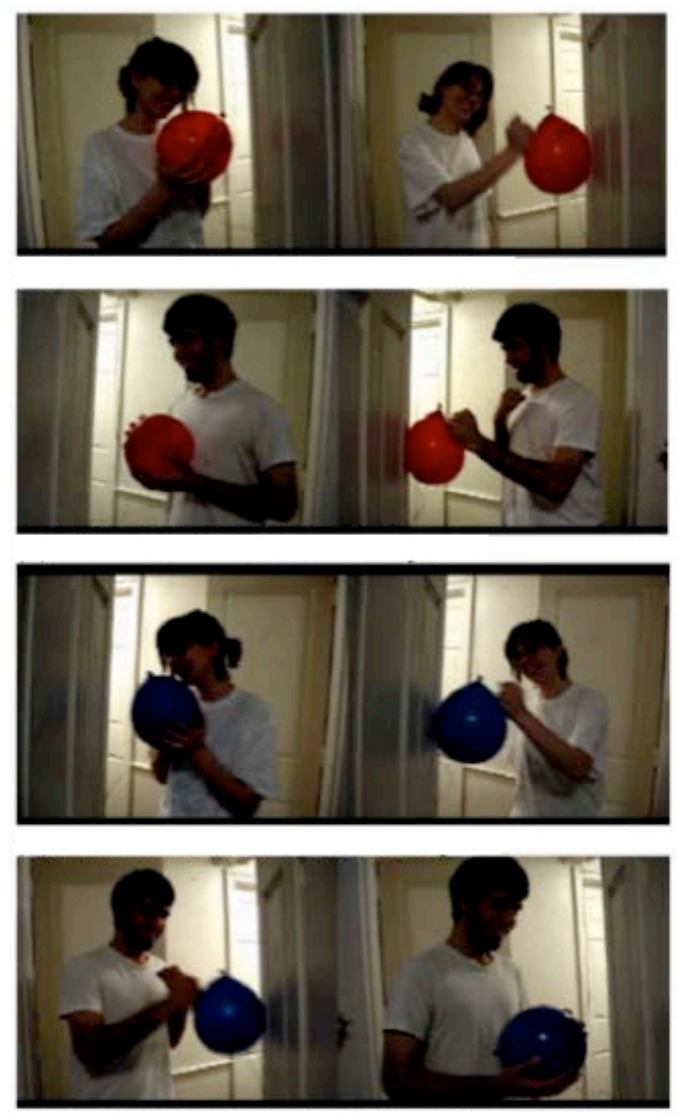

Figure 2. Four pairs of clips of the male and female models hitting and cradling the balloon.

The third part of the procedure was identical to the first part. The same balloon was provided for another 120 seconds.

\subsection{Measures}

Three pairs of coders rated the videotapes. One pair continually recorded the infants' looking preferences in milliseconds for each of the 32 6-second blocks. A second pair recorded for each of 240 seconds (120 pre-model and 120 post-model) whether infants cradled the balloon with two hands. The third pair recorded for each of 240 seconds whether infant hit the balloon 
with one hand (see Figure 3 for examples). For all three measures, the ratings of two coders within a pair were averaged.
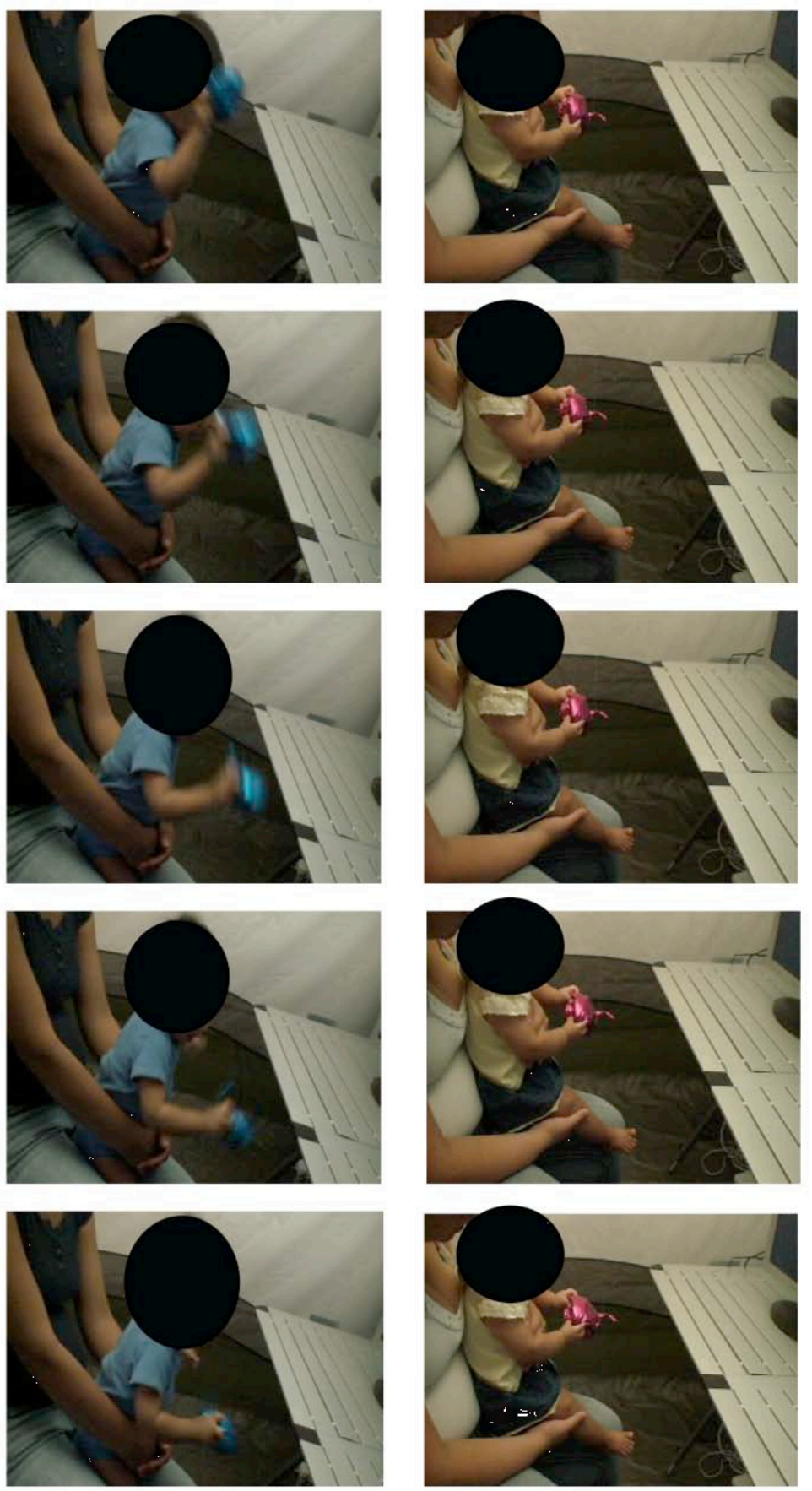

Figure 3. An example of an infant hitting and cradling the balloon. 
The looking preference measure was sub-divided into two additional measures: total number of seconds of looking across all eligible blocks, and proportion of time looking at hitting versus cradling within a block averaged across all eligible blocks. Eligible blocks were defined as those in which infants looked at the videos for at least $1500 \mathrm{~ms}$ ( $25 \%$ of the time) in keeping with standard procedures (Benenson, et al., 2004).

Coders were unaware of the procedure and hypotheses and worked independently. Videotapes of infants' movements before and after observing the model were interleaved, so that coders rated half of the post-model movements prior to coding the pre-model movements.

Reliability for looking preferences between coders was computed using Pearson productmoment correlations on number of milliseconds looking right and left and not looking for every block for each infant. The mean correlation between coders was .87 , yielding an effective reliability of .93. Reliability for cradling was calculated by tabulating the total number of seconds an infant cradled the balloon. The correlation between coders across infants was .88, with an effective reliability of .94. Additionally, videotapes of 12 infants were randomly selected, and Cohen's kappa for cradling was calculated, yielding a mean kappa of .65. Reliability for hitting was calculated by tabulating the number of seconds that an infant hit the balloon, yielding a correlation of .91, with an effective reliability of .95 . Cohen's kappa for hitting calculated on the same 12 infants produced a mean kappa of .83.

\subsection{Results}

A preliminary repeated measures analysis of variance (ANOVA) on infants' absolute looking times to the female versus male models with infants' sex as the independent variable 
showed no sex differences occurred in looking time, $F(1,43)=0.89$, n.s. Consistent with a prior finding that 3- to 4-month old infants look more at female adults (Quinn, Yahr, Kuhn, Slater, \& Pascalis, 2002), infants of both sexes looked slightly more at the female model (males: $M=$ $77.20 \mathrm{~s}, S D=2.80$; females: $M=80.92 \mathrm{~s}, S E=2.87$ ) than the male model (males: $M=74.3 \mathrm{~s}, S E=$ 2.77; females: $M=78.1 \mathrm{~s}, \mathrm{SE}=3.02), F(1,43)=7.82, p=.008)$.

A repeated measures ANOVA on mean proportion of time looking at hitting (versus cradling) by the female and male adult with infants' sex as the independent variable yielded no significant effects, all $F_{\mathbf{S}}<1$. $T$-tests however showed that male infants spent proportionally more time than chance looking at hitting (versus cradling) by both the female model, $M=.55, S E=$ $.01 ; t(24)=2.83, p=.009$, and the male model, $M=.54, S E=.02 ;(\mathrm{t}(24)=2.31, p=.03$. Female infants did not differ from chance in their proportion of time looking at hitting (versus cradling) by either the female model, $M=.53, S E=.02 ; t(19)=1.64$, n.s, or the male model, $M=.52, S E$ $=.02, t(19)=1.11$, n.s.

A repeated measures ANOVA on the number of seconds infants cradled the balloon before and after viewing the model with infants' sex as the independent variable yielded no significant effects (pre-model males: $M=17.80, S E=2.99$ and females: $M=14.20, S E=4.26$; post-model males: $M=12.48, S E=2.88$ and females: $M=12.05, S E=2.93)$. Cradling diminished but not significantly after viewing the models.

To examine the hypothesis that male infants increase their hitting after viewing the models' hitting, a repeated measures ANOVA was conducted on the number of seconds infants spent hitting the balloon before and after viewing the model with infants' sex as the independent variable. Results yielded a main effect of Time, $F(1,43)=10.75, p=.002$, which was qualified 
by the predicted Sex X Time interaction, $F(1,43)=5.68, p=.02$. Tukey tests, $p<.05$, showed that male infants increased their hitting after viewing the models, whereas female infants did not (see Figure 4), with $d=.70$ for males' increase in hitting. Illustrating the difference, no female infant $(0 / 20)$ increased her hitting by more than 5.5 seconds, compared with $8 / 25(32 \%)$ of male infants who did so, $X^{2}(1)=7.78, p=.005$.

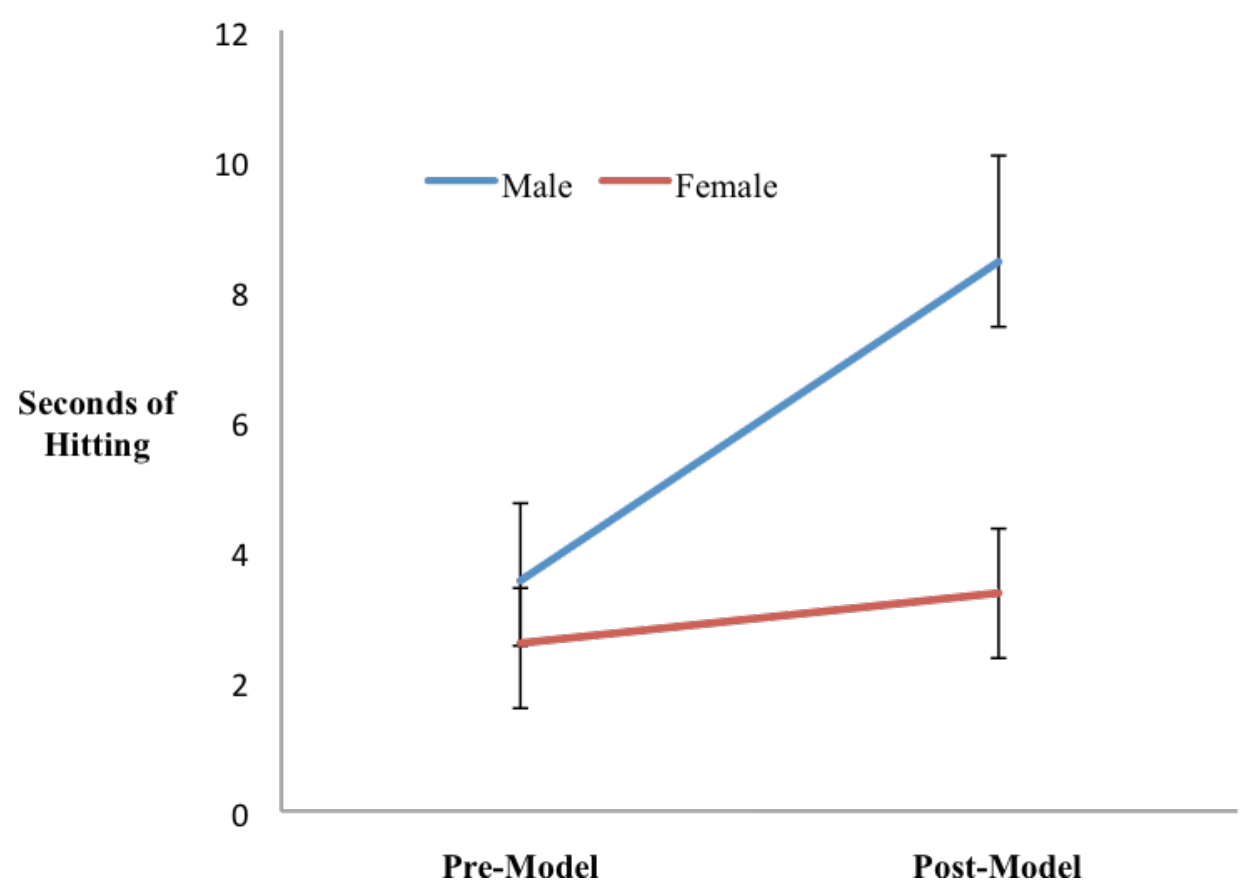

Figure 4. Mean (and standard error) number of seconds of hitting by male and female infants before and after viewing the models.

To examine the possibility that this effect was due to male infants' spontaneously increasing their propulsive movements over time, number of seconds of hitting was calculated separately for the first and second minutes before viewing the model and the first and second minutes after viewing the model. A repeated measures ANOVA with time (pre- and post-model) 
and minute (first or second) was conducted with infants' sex as the independent variable. None of the effects of time was significant. Before viewing the models, infants of both sexes increased their hitting from the first to the second minute, but not significantly. After viewing the models, males did not increase their hitting between the first and second minutes (see Table 1).

Table 1

Mean (and standard error) number of seconds hitting in first and second minutes before and after viewing the model

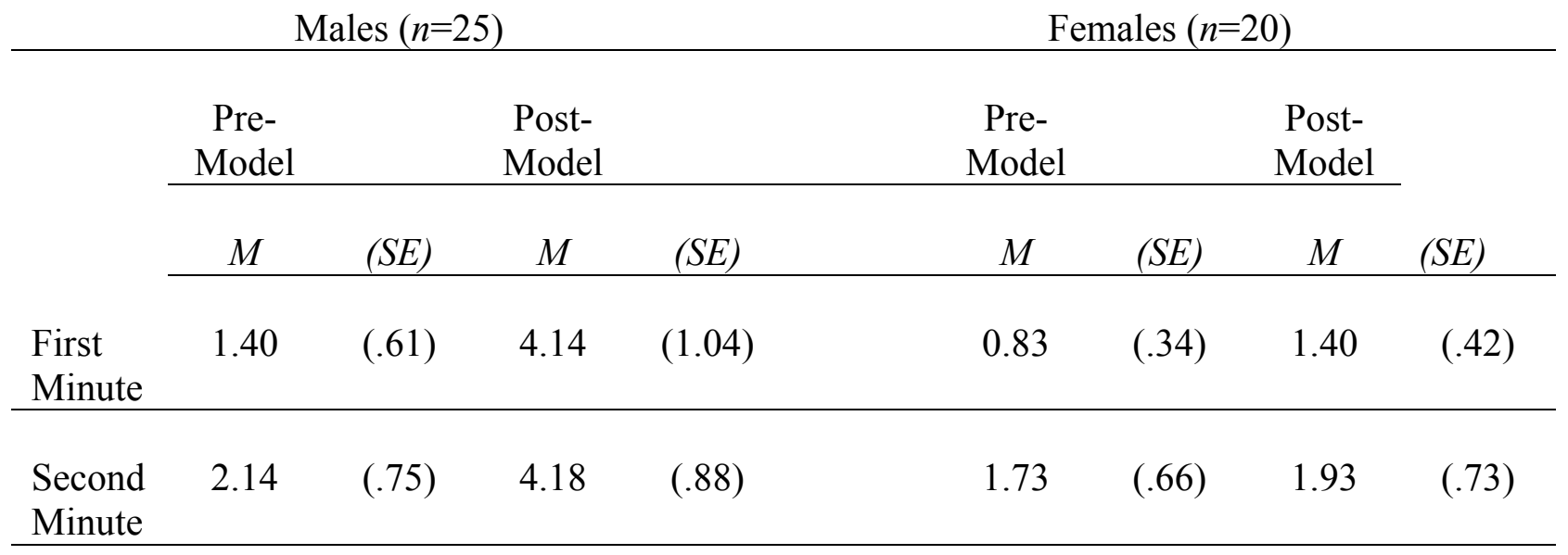

Finally, to examine whether male infants selectively imitated the male model, we computed the correlation between the proportion of time an infant spent looking at the male model's hitting (versus cradling) and the number of seconds by which an infant increased his hitting after viewing the videos. As predicted based on Bandura's results, increases in hitting by male infants were positively correlated with looking at the male model's hitting $\mathrm{r}(23)=.57, p=$ .003 , but not with looking at the female model's hitting, $r(23)=.12$, n.s., $t(22)=2.14, p=.03$. When the same correlations were computed for female infants, the correlation was not significant 
for the male model, $\mathrm{r}(18)=.23$, n.s., or the female model, $\mathrm{r}(18)=.31$, n.s.

Critically, no evidence emerged that male infants had been trained to hit the balloon more than female infants. Before viewing the videos, male and female infants did not differ in number of seconds hitting the balloon (see Figure 4). Further, for male infants, number of seconds hitting the balloon before viewing the models was unrelated to the proportion of time they spent looking at the male adult model's hitting (versus cradling), $\mathrm{r}(23)=-.20$, n.s. and to the amount they increased their hitting, $\mathrm{r}(23)=-.27$, n.s. Thus, it was not the case that male infants who initially hit more were more attracted to the male model's hitting or more likely to increase their own hitting.

As a final set of analyses, all computations were repeated with age as a covariate. None of the effects was modified.

\subsection{Discussion}

Male infants imitated propulsive motion more than female infants did. The extent of this effect correlated positively with the proportion of time spent viewing the male model hitting a balloon. Three interpretations arise.

First, male infants may consciously label themselves and the adults by gender then selectively imitate the motions of the male adult that are associated with male behavior (Zosuls et al., 2009). Although infants do learn implicitly to categorize adults by gender as early as 3 months of age (Quinn, et al., 2002), no evidence exists that infants younger than 17 months can consciously label themselves or others by gender or conclude that propulsive movement is associated with male behavior. Thus, we think it highly unlikely that 6-9 month-old male infants are capable of explicitly matching their own and another's gender, then preferentially imitating 
male sex-typed behavior.

Second, fathers may have reinforced their sons, but not their daughters, for exhibiting propulsion. While some studies support fathers' greater motor stimulation of infant sons than daughters (Parke, 1996), many do not (Lytton \& Romney, 1991; Konner, 2005; Maccoby, 1998; Parke, 1996). Further, fathers' unique motor stimulation of infants generally consists of tossing the infant in the air, or bouncing or shaking the infant (Parke, 1996), not propulsive motion. Finally, because no sex differences in initial propulsive movements towards the balloon were obtained in this study, this interpretation also appears unlikely. Nevertheless, it remains possible that the videos reminded males of fathers' selective reinforcement of their propulsive movements.

Third, males may be more attracted innately than females to propulsive movement. This interpretation is consistent with research on prenatally androgenized girls and on non-human primates demonstrating a relation between higher androgen levels and greater propulsive movements and with findings that human sex differences in throwing force emerge by 3 years (Thomas \& French, 1985; Watson, 2001).

Why male infants' increase in hitting correlated with their proportion of viewing the male model's hitting requires further investigation. We speculate that many male infants found the male model's propulsive movements more appealing than those of the female. After puberty, males' throwing force increases so markedly that little overlap exists between the sexes (Thomas \& French, 1985). In our study, videotapes show that the male adult hit the balloon more straightforwardly than the female adult who tilted her head and softened her blow (see Figure 2). Research using a between-subjects design with male and female models must examine imitation 
of propulsive movements at different ages to determine more precisely how experience with observing and executing propulsion influences its development.

If this latter interpretation proves accurate, this suggests that propulsion may form one basis for future male sex-typed activities. According to the theory of embodied cognition (Mahon \& Caramazza, 2009), bodily movement guides the formation of concepts and subsequent behavior. Infant males as they develop may preferentially select toys, activities, and interests partially because these afford the opportunity to engage in propulsive movement. Differential adult reinforcement of culturally prescribed sex-typed behavior, along with gender self-labeling followed by subsequent imitation of same-sex models would accentuate already existing bodily movement preferences. Alternative mechanisms, such as perceptual attraction to individual faces, may produce other sex-typed preferences. Additional research must define propulsive movement more precisely along with its manifestations in toy and activity preferences.

\subsection{Conclusions}

The current research demonstrates that male more than female infants imitate propulsive movements of a male adult model. Future research must examine sex-differentiated preferences early in infancy and the extent to which they guide future sex-typed activities and interests.

\section{Acknowledgements}

We thank David Osler and the staff of the Cambridge Health Alliance for their invaluable assistance, as well as the Goelet Fund, the Mary Gordon Roberts Fellowship, Harvard College 
Research Program, and Dean's Summer Research Award for support. We also thank Anastasyia Yakhkind for help with data collection; Matthew Garcia, Ashley Jovanovski, Timothy Kim, Jennifer McKee, Amy Tao, and Beau Tremitiere, for assistance with coding; and Henry Markovits for technical assistance.

\section{References}

Alexander, G. M., \& Hines, M. (2002). Sex differences in response to children's toys in nonhuman primates (Cercopithecus aethiops sabaeus). Evolution and Human Behavior, 23(6), 467-479.

Alexander, G. M., Wilcox, T., \& Woods, R. (2009a). Sex differences in infants' visual interest in toys. Archives of Sexual Behavior, 38(3), 427-433. doi: 10.1007/s10508-008-9430-1

Bandura, A., \& Bussey, K. (2004). On broadening the cognitive, motivational,and sociocultural scope of theorizing about gender development and functioning: Comment on Martin, Ruble, and Szkrybalo (2002). Psychological Bulletin, 130, 691-701.

Bandura, A., \& Huston, A. C. (1961). Identification as a process of incidental learning. The Journal of Abnormal and Social Psychology, 63(2), 311-318. doi: 10.1037/h0040351

Bandura, A., Ross, D., \& Ross, S. A. (1961). Transmission of aggression through imitation of aggressive models. The Journal of Abnormal and Social Psychology, 63(3), 575-582.

Benenson, J. F., Duggan, V., \& Markovits, H. (2004). Sex differences in infants' attraction to group versus individual stimuli. Infant Behavior \& Development, 27(2), 173-180.

Benenson, J., Liroff, E., Pascal, S., \& Della Cioppa, G. (1997). Propulsion: A behavioral expression of masculinity. British Journal of Developmental Psychology, 15, 3750. 
Berenbaum, S. A., \& Hines, M. (1992). Early androgens are related to childhood sex-typed toy preferences. Psychological Science, 3(3), 203-206.

Berenbaum, S. A., \& Snyder, E. (1995). Early hormonal influences on childhood sex-typed activity and playmate preferences: Implications for the development of sexual orientation. Developmental Psychology, 31(1), 31-42.

Campbell, A., Shirley, L., Heywood, C., and Crook, C. (2000). Infants' visual preference for sexcongruent babies, children, toys and activities: A longitudinal study. British Journal of Developmental Psychology, 18, 479-498.

Connellan, J., Baron-Cohen, S., Wheelwright, S., Batki, A., \& Ahluwalia, J. (2000). Sex differences in human neonatal social perception. Infant Behavior \& Development, 23(1), 113-118.

Gosso, Y., Otta, E., Morais, M. d. L. S. e., Ribeiro, F. J. L., \& Bussab, V. S. R. (2005). Play in Hunter-Gatherer Society. In A. D. Pellegrini \& P. K. Smith (Eds.), The nature of play: Great apes and humans. (pp. 213-253). New York, NY US: Guilford Press.

Hassett, J. M., Siebert, E. R., \& Wallen, K. (2008). Sex differences in rhesus monkey toy preferences parallel those of children. Hormones and Behavior, 54(3), 359-364.

Huston, A. C. (1986). The development of sex typing: Themes from recent research. Annual Progress in Child Psychiatry \& Child Development, 168-186.

Kahlenberg, S., and Wrangham, R.W. (2010). Sex differences in chimpanzees' use of sticks as play objects resemble those of children. Current Biology 20, 1067-1068.

Kohlberg, L. (1966). A cognitive-developmental analysis of children's sex-role concepts and attitudes. In E. E. Maccoby (Ed.), The development of sex differences (pp. 82-173). Stanford, CA: Stanford University Press. 
Konner, M. (2005). Hunter-gather infancy and childhood. In B. S. Hewlett \& M. E. Lamb (Eds.), Hunter-gatherer childhoods (pp. 19-64). New Brunswick, NJ: Transaction.

Lytton, H., \& Romney, D. M. (1991). Parents' differential socialization of boys and girls: A meta-analysis. Psychological Bulletin, 109(2), 267-296.

Maccoby, E. E. (1998). The two sexes: Growing up apart, coming together. Cambridge, MA US: Belknap Press/Harvard University Press.

Mahon, B. Z., \& Caramazza, A. (2009). Concepts and categories: A cognitive europsychological perspective. Annual Review of Psychology, 60, 27-51.

Martin, C. L., Ruble, D. N., \& Szkrybalo, J. (2002). Cognitive theories of early gender development. Psychological Bulletin, 128, 903-933.

Öhman, A., \& Mineka, S. (2003). The malicious serpent: Snakes as a prototypical stimulus for an evolved module of fear. Current Directions in Psychological Science, 12(1), 5-9. doi: $10.1111 / 1467-8721.01211$

Parke, R. D. (1996). Fatherhood. Cambridge, MA US: Harvard University Press.

Pasterski, V. L., Geffner, M. E., Brain, C., Hindmarsh, P., Brook, C., \& Hines, M. (2005). Prenatal hormones and postnatal socialization by parents as determinants of male-typical toy play in girls with Congenital Adrenal Hyperplasia. Child Development, 76(1), 264278.

Quinn, P. C., Yahr, J., Kuhn, A., Slater, A. M., \& Pascalis, O. (2002). Representation of the gender of human faces by infants: A preference for female. Perception, 31(9), 11091121.

Ruble, D. N., Martin, C. L., \& Berenbaum, S. A. (2006). Gender Development. In N. Eisenberg, W. Damon \& R. M. Lerner (Eds.), Handbook of child psychology: Vol. 3, Social, 
emotional, and personality development (6th ed.). (pp. 858-932). Hoboken, NJ US: John Wiley \& Sons Inc.

Scarr, S., \& McCartney, K. (1983). How People Make Their Own Environments: A Theory of Genotype $\rightarrow$ Environment Effects. Child Development, 54, 424-435.

Serbin, L. A., Poulin-Dubois, D., Colburne, K. A., Sen, M. G., \& Eichstedt, J. A. (2001). Gender stereotyping in infancy: Visual preferences for and knowledge of gender-stereotyped toys in the second year. International Journal of Behavioral Development, 25(1), 7-15. doi: $10.1080 / 01650250042000078$

Thomas, J. R., \& French, K. E. (1985). Gender Differences Across Age in Motor Performance: A Meta-Analysis. Psychological Bulletin, 98, 260-282.

Watson, N. V. (2001). Sex differences in throwing: Monkeys having a fling. Trends in Cognitive Sciences, 5(3), 98-99.

Wood, W., \& Eagly, A. H. (2002). A cross-cultural analysis of the behavior of women and men: Implications for the origins of sex differences. Psychological Bulletin, 128(5), 699-727. doi: $10.1037 / 0033-2909.128 .5 .699$

Zosuls, K. M., Ruble, D. N., Tamis-LeMonda, C. S., Shrout, P. E., Bornstein, M. H., \& Greulich, F. K. (2009). The acquisition of gender labels in infancy: Implications for gender-typed play. Developmental Psychology, 45(3), 688-701. 